\title{
Computer Vision Syndrome and Associated Factors among Students of Faculty of Medicine, Cairo University
}

\author{
MARWA M. AHMED, M.D.*; NAGWA E. SAAD, M.D.*; EHSAAN M. ALMEHELMY, M.D.** and \\ FATMA F. YOUSEF, M.Sc.*
}

The Departments of Family Medicine* and Ophthalmology**, Faculty of Medicine, Cairo University, Egypt

\begin{abstract}
Background: Computer Vision Syndrome (CVS) is an emerging health problem which is unceasingly increasing worldwide. It refers to a group of eye and vision problems experienced during or related to computer and other VDTs use.
\end{abstract}

Aim of Study: The objectives were to determine the prevalence of CVS among students of Faculty of Medicine in Cairo University and to detect the relation of various factors in computer use with occurrence of symptoms.

Patients and Methods: This study is a cross-section study in which 260 medical students from different grades of Faculty of Medicine in Cairo University were included. Participants were interviewed using self-administered Computer Vision Syndrome Questionnaire (CVS-Q).

Results: The current study reveals that $75 \%$ of medical students in Faculty of Medicine suffered from CVS. Headache $(81.5 \%)$ and eye pain $(63.8 \%)$ are the most frequent CVS symptoms experienced by the students. CVS prevalence is found to be more among female students $(78.7 \%)$ than among male ones $(71 \%)$. It is also found to be more among glasses wearers $(78.8 \%)$ than among non-glasses wearers $(70.7 \%)$ and much more among contact lenses wearers $(92.9 \%)$ than among non-contact lenses wearers (72.8\%). There is significant linear correlation between duration of use of VDTs (by hours/ day) and the score of CVS.

Conclusion: This study revealed that CVS is a prevalent problem among students of Faculty of Medicine, Cairo University.

Key Words: Computer vision syndrome - Medical students Computers use-Laptops.

\section{Introduction}

IN the era of technology advancement, the use of computers and other electronic devices has become

Correspondence to: Dr. Marwa M. Ahmed, E-Mail: marwamostafa@kasralainy.edu.eg crucial and vital in all aspects of our daily life. All age groups whether adults and children are using computers and other electronic devices for professional and leisure purposes. Millions of people spend hours using Video Display Terminal (VDT) which include smartphones, laptops, tablets and others [1].

The great benefits of using these devices cannot be denied but on the other hand, it can cause many health hazards if used improperly. These health hazards include visual and musculoskeletal problems. Common musculoskeletal complains include fingers tingling, cervical stiffness and backache. Prolonged usage can cause various visual symptoms that is known as Computer Vision Syndrome (CVS) [2]. The definition of CVS as stated by the American Optometric Association is "a complex of eye and vision problems related to activities, which stress the near vision, and which are experienced in relation or during the use of computer" [3]

CVS symptoms includes redness, dry eyes, blurred vision, burning sensation and other symptoms of eye strain. Usually these symptoms last for short period of time and resolve after rest. But it has negative impact on productivity and quality of life, increased error rate and reduced job satisfaction [4]. Therefore, it is considered a global public health problem as more than 60 million people suffer from CVS worldwide and its incidence is around 1 million [5].

It is essential to conduct studies to address CVS and its severity. To our knowledge, few studies were done to detect the prevalence of CVS in Middle Eastern countries and no studies assess the magnitude of the problem in Cairo, Egypt. In this study, we tried to assess the prevalence of CVS 
among medical students in Cairo University. This will help to increase the awareness of medical student about health hazards of VDTs.

\section{Patients and Methods}

This cross-sectional study was conducted in Faculty of Medicine, Cairo University, from March 2016 till March 2017.

\section{Sample size:}

Using Epicalc 2000, sample size was calculated using the following input: Prevalence of CVS among medical students was $79 \%$ according to a study done by Logaraj et al., in 2014 [6], significant level of 0.05 and power of $95 \%$, the total sample size was 254 participants to be increased to 260 participants. A stratified random sample according to the grade was done.

\section{Inclusion and exclusion criteria:}

Students from different grades in the faculty who approved to participate in the study were included in the study. Students who had recent eye operations up to 1 year ago and students who have eye disease at time of the study or chronic eye problems were excluded.

\section{Study tool:}

Self-administered questionnaire which consists of 2 parts. The first part assesses their pattern of computer use, other factors that may influence occurrence of symptoms (average time of sleeping and practicing other activities requiring near vision), and whether they are wearing glasses or lenses. The second part is the CVS-Q [7] (Crespo et al., 2015), which assesses the frequency and intensity of 16 symptoms of CVS. The severity is calculated by multiplying the frequency by the intensity then it is given a score of either 0,1 or 2 . The subject is considered to have CVS if the total score of the severity of the 16 symptoms is $\geq 6$. The sensitivity and specificity of the questionnaire is over $70 \%$.

The questionnaire was tested on 20 students from different grades. Most of the students did not answer the question asking about the visual acuity so it was deleted from the questionnaire.

\section{Statistical methods:}

Data were coded and entered using the statistical package SPSS Version 21. Data were summarized using number and percent for qualitative variables while mean, standard deviation, median and interquartile range were used for quantitative variables.
Comparison between groups were done using Chisquare test for qualitative variables. In nonparametrical, Mann-whitney test was used to compare quantitative variables which are not normally distributed. Correlations were done to test for linear relations between variables. $p$-values less than or equal to .05 were considered as statistically significant.

\section{Ethical consideration:}

Permission for using CVS-Q was obtained from the author in February 2016. The research and ethical committee approval of the study was taken in April 2016. The vice dean permission for collecting questionnaires from the students was taken in April 2016. Written consent was taken from all the participants after explaining the aim of the study to them.

\section{Results}

Two hundred and sixty students were included in the study, their age ranged from 17 to 25 years with a mean age $20.82 \pm 1.83$ years. Around $48 \%$ of them were male while $52.3 \%$ were female students. Almost similar numbers of students are taken from each grade (average 43 students from each grade).

Around $50 \%$ of the medical students do not wear neither glasses or contact lenses while $41.9 \%$ of the students wear glasses only, and $10.8 \%$ wear both glasses and contact lenses. Only $4 \%$ of students use the screens at a level above the eye level while $58 \%$ of them use screens at the eye level. Those who use screens at level below the eye level represent $38 \%$.

It was found that the duration of computer or laptop use by years (mean $=8.87 \pm 3.53$ years) is more than duration of other VDTs use by years (mean $=6.14 \pm 2.79$ years). On the contrast, duration of use by number of hours per day for computer or laptop (with mean $=3.28 \pm 2.24$ hours) is less than that of other VDTs (with mean $=5.63 \pm 3.5$ hours).

Sleeping hours of the students range from 212 hours with a median of $7 \pm 1.47$ and time spent by the students practicing other activities that need near vision range from $0-12$ with a mean of $5.3 \pm$ 2.43 hours.

Regarding CVS, the score achieved by the students ranges from 0 to 27 (considering that score equal to or more than 6 is CVS +ve and score below 6 is CVS $-v e$ ). Seventy five percent of 
medical students suffered from computer vision syndrome and considered CVS +ve while only $25 \%$ of them are considered CVS -ve and didn't suffer from the syndrome. The most frequent three symptoms experienced by the students are headache $(81.5 \%)$ followed by eye pain $(63.8 \%)$ followed by tearing $(58.8 \%)$ while the least frequent symptom is double vision which is experienced by $18.5 \%$ only as shown in (Table 1).

Table (2) shows that $71 \%$ of male students suffered from CVS while affected female students represent $78.7 \%$ but this is not statistically significant $(p$-value $=.152)$. About half of the students of the 4 th grade $(54 \%)$ are classified to be CVS +ve and this is the least percent of students among all the grades.

There is statistically significant difference ( $p$ value $=.046$ ) in number of sleeping hours between the two groups, CVS +ve group (with mean $=7.24$ hours, median $=7$ hours, range $=2-12$ ) and CVS - ve group (with mean $=7.63$ hours, median $=8$ hours, range $=5-12$ ).

There is no statistically significant difference in duration of use of computer or laptop (either by years or hours/day) between CVS +ve group and CVS -ve group. On the contrast, and there is statistically significant difference $(p$-value $=.038)$ between duration of use of other VDTs by years in the CVS +ve group (with mean=6.34 years, median $=6$ years, range $=1-15$ ) and CVS - ve group (with mean $=5.54$ years, median $=5$ years, range $=1$ 12). Also, the duration of use of other VDTs by hours/day in the CVS +ve group (with mean $=5.98$ hours, median $=5$ hours, range $=1-18$ ) is more than its duration in CVS -ve group (with mean $=4.57$ hours, median $=3$ hours, range $=1-16$ ) and this is also statistically significant ( $p$-value $=.001$ ). Moreover, the total duration of use of all screens by hours/day in the CVS +ve group (with mean $=9.34$ hours, median $=9$ hours, range $=2-20$ ) is more than the total duration of use by the other group (with mean $=7.62$ hours, median $=7$ hours, range $=2-17$ ) and this is statistically significant ( $p$-value $=.002$ ).

As shown in (Table 3), there is statistically significant difference medical students suffering from CVS and those who are not suffering from CVS regarding wearing contact lens. Also, there is significant correlation between duration of use of other VDTs by hours/day and the score of CVS (Table 4).
Table (1): Frequency of symptoms of CVS among medical students during the academic year 2016-2017.

\begin{tabular}{lcc}
\hline & \multicolumn{2}{c}{ Total } \\
\cline { 2 - 3 } Symptom & Number & Percent (\%)* \\
\hline 1- Burning & 139 & 53.5 \\
2- Ithching & 119 & 45.8 \\
3- Feeling of foreign body & 88 & 33.8 \\
4- Tearing & 153 & 58.8 \\
5- Excessive blinking & 117 & 45 \\
6- Eye redness & 149 & 57.3 \\
7- Eye pain & 166 & 63.8 \\
8- Heavy eyelids & 91 & 35 \\
9- Dryness & 101 & 38.8 \\
10- Blurred vision & 149 & 57.3 \\
11- Double vision & 48 & 18.5 \\
12- Difficult focusing for near objects & 118 & 45.4 \\
13- Increased sensitivity to light & 145 & 55.8 \\
14- Coloured halos around objects & 84 & 32.3 \\
15- Feeling sight is worsening & 134 & 51.5 \\
16- Headache & 212 & 81.5 \\
\hline
\end{tabular}

*: Percent within the gender

Table (2): Percent of CVS among male \& female students and among students of different grades during the academic year 2016-2017.

\begin{tabular}{llllllll}
\hline \multirow{2}{*}{ Score } & \multicolumn{2}{c}{ CVS +ve } & \multicolumn{2}{c}{ CVS -ve } & \multicolumn{2}{c}{ Total } & $\begin{array}{c}p- \\
\text { value }\end{array}$ \\
\cline { 2 - 6 } Variable & $\mathrm{N}^{* *}$ & $\%^{*}$ & $\mathrm{~N}$ & $\%$ & $\mathrm{~N}$ & $\%$ & \\
\hline Gender: & & & & & & & \\
Male & 88 & 71 & 36 & 29 & 124 & 100 & 0.152 \\
Female & 107 & 78.7 & 29 & 21.3 & 136 & 100 & \\
Grade: & & & & & & & \\
1st & 34 & 77 & 10 & 23 & 44 & 100 & .033 \\
2nd & 34 & 77 & 10 & 23 & 44 & 100 & \\
3rd & 37 & 80 & 9 & 20 & 46 & 100 & \\
4th & 22 & 54 & 19 & 46 & 41 & 100 & \\
5th & 33 & 79 & 9 & 21 & 42 & 100 & \\
6th & 35 & 81 & 8 & 19 & 43 & 100 & \\
\hline
\end{tabular}

*: Percent $(\%)$ within the variable

$* * \mathrm{~N}$ : Number.

Table (3): Relations between different variables and score of CVS among students of different grades during the academic year 2016-2017.

\begin{tabular}{|c|c|c|c|c|c|c|c|}
\hline \multirow[b]{2}{*}{ The variable } & \multicolumn{2}{|c|}{ CVS +ve } & \multicolumn{2}{|c|}{ CVS -ve } & \multicolumn{2}{|c|}{ Total } & \multirow{2}{*}{$\begin{array}{c}p- \\
\text { value }\end{array}$} \\
\hline & $\mathrm{N}^{* *}$ & $\% *$ & $\mathrm{~N}$ & $\%$ & $\mathrm{~N}$ & $\%$ & \\
\hline \multicolumn{8}{|l|}{ Wearing glasses: } \\
\hline Yes & 108 & 78.8 & 29 & 21.2 & 137 & 100 & .132 \\
\hline No & 87 & 70.7 & 36 & 29.3 & 123 & 100 & \\
\hline \multicolumn{8}{|l|}{ Wearing contact lenses: } \\
\hline Yes & 26 & 92.9 & 2 & 7.1 & 28 & 100 & .021 \\
\hline No & 169 & 72.8 & 63 & 27.2 & 232 & 100 & \\
\hline \multicolumn{8}{|l|}{ Level of the screen: } \\
\hline Above eye level & 10 & 90.9 & 1 & 9.1 & 11 & 100 & .460 \\
\hline At eye level & 112 & 74.2 & 39 & 25.8 & 151 & 100 & \\
\hline Below eye level & 73 & 74.5 & 25 & 25.5 & 98 & 100 & \\
\hline \multicolumn{8}{|l|}{ Type of light: } \\
\hline Flurescent light & 148 & 76.3 & 46 & 23.7 & 194 & 100 & .422 \\
\hline Natural light & 26 & 66.7 & 13 & 33.3 & 39 & 100 & \\
\hline Light of the source & 21 & 77.8 & 6 & 22.2 & 27 & 100 & \\
\hline
\end{tabular}

*: Percent (\%) within the variable.

$* * \mathrm{~N}$ : Number. 
Table (4): Correlations between different quantitative variables and score of CVS: (Spearman's rho).

\begin{tabular}{ll}
\hline The variable & Score of CVS \\
\hline Age: & \\
Correlation Coefficient & $-.050-$ \\
Sig. (2-tailed) & .424 \\
Use computer or laptop (Years): & \\
$\quad$ Correlation Coefficient & .017 \\
Sig. (2-tailed) & .791 \\
Use computer or laptop (Hours/day): & \\
Correlation Coefficient & .067 \\
Sig. (2-tailed) & .285 \\
VDTs use (years): & \\
Correlation Coefficient & .103 \\
Sig. (2-tailed) & .096 \\
VDTs use (Hours/day): & \\
Correlation Coefficient & $.208^{* *}$ \\
Sig. (2-tailed) & .001 \\
Time of sleeping (Hours): & \\
Correlation Coefficient & $-.083-$ \\
Sig. (2-tailed) & .181 \\
Time of practice activities need near vision (Hours): & \\
Correlation Coefficient & .060 \\
Sig. (2-tailed) & .339 \\
\hline
\end{tabular}

**: Correlation is significant at the 0.01 level (2-tailed).

\section{Discussion}

The aim oftthissstudly weas ttoddermine the prevalence of CVS among students offfeculity off medicime in Cairo University and to dettect the relation of warious factors writth occumence of symptoms from the total of 280 sstudy pattioipants, 75\% of Kassr All- iimy meedical sstuthentsssuffereet from CVS. This finding is consistent with the work of Iqbal et al., in 2018 [8], whene $86 \%$ of the medtical students in Sohag University im Fggypt sufffered from one or more off symptoms ofCWSS whem they use díital screens for 3 hourss cormoreprddiay. Similarly, Reddy and colleagmes im 20113 [9] reported that the prevalence of one or mone syymptioms of CVS among 795 Malaysian University sturdemts was $89.9 \%$ when the daily usse off digitital ssoreens was 2 hours or more. In contrast to tifhat, $\mathrm{K}$ hhoulat al., in 2016 [10] reported that $67.2 \%$ off undergnatduate medical students experienced at lleast cone symptom related to CVS. This dilffferemoe im the prevalence of CVS may be due too the difffereence in the method used to commsiidter the ssultjecat ass affected by CVS or not. The ofther sturdies comsittered experiencing one or more symptoms as beiing affected by CVS. Whille in the courrentsstuty, theing

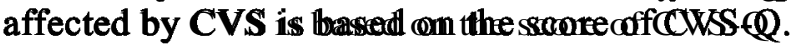

In the current study, there is diinect commellation between durratiom of usse of other VDTs by hours//day and the score of CVS. Also, All Rashindiand Althumaidan in 20117 [[11]] and Khola and her collexgues in 2016 [10] reported significant association between the development of CVS and use of computer for longer duration. Many other investigators reported the same findings [12-14]

In our study, headache $(81.5 \%)$, eye pain $(63.8 \%)$ and excessive tearing $(58.8 \%)$ are the most frequent CVS symptoms experienced by the students. In another study conducted by Logaraj et al., in 2014, found that headache and dry eye were the most common symptoms experience by medical students [6]. While Agarwal and his colleagues in 2013 [15], reported that the most frequent ocular symptoms were eye strain (53.8\%), itching (47.6\%) and burning (66.7\%).

In the current sturdy, thene wass mo siginifficant relation between the age oftthermeeticed lsstuatentss and occurremce of syymomptoms ofCCUSS. Alkso, ZZatinuddin \& Isa in 2014 foumd mo siignifficantrassociation between age and CWSS [16]. This was not the case in the sttudy dome by Rramassiingoge amd hins colleagues in 20116 [14], where the prevalence of CWS increased with the iimcreasing age off the computer user. The differemce bettween tthesstudiess may be due to the difference in the age of sturdy participants as the age of theeppattioippantss intthe study of Raramsingthe eat all,,200116rrangeed ffrom 1188 to 60 years.

Limitatioms of the studty iindlude iinabilility tto perform ophthalmic examination to the meediced students and neck and shoulder paim is not imcluded in the symptoms of CVS-Q and thus not imclunded in the calculated

\section{Conclusion:}

The current study reveals that $75 \%$ of medical students in faculty of medicine suffered from CVS, with the most experienced symptoms of headache and blurred vision.

\section{References}

1- AL TAWIL L., ALDOKHAYEL S., ZEITOUNI L., QADOUMI T., HUSSEIN S. and AHAMED S.: Prevalence of self-reported computer vision syndrome symptoms and its associated factors among university students. European Journal of Ophthalmology, Vol. 30 (1): 189-95, DOI: 10.1177/1120672118815110 PMID:30474390, 2020.

2- AKINBINU T.R. and MASHALLA Y.J.: Impact of computer technology on health: Computer Vision Syndrome (CVS). Medical Practice and Reviews, 5: 20-30, 2014.

3- American Optometric Association. Computer vision syndrome: Protecting your eyes at work, https://www.aoa.org /patients-and-public/caring-for-your-vision/protectingyour-vision/computer-vision-syndrome (accessed 20 October 2019). 
4- WIMALASUNDERA S.: Computer vision syndrome Galle Medical Journal; 11 (1): 25-9, doi: 10.4038/ gmj.v11i1.1115, 2006.

5- RANASINGHE P., WATHURAPATHA W.S., PERERA Y.S., et al.: Computer vision syndrome among computer office workers in a developing country: An evaluation of prevalence and risk factors. BMC Res. Notes; 9: 150, doi: 10.1186/s13104-016-1962-1 PMID: 26956624, 2016.

6- LOGARAJ M., MADHUPRIYA V., and HEGDE S.: Computer vision syndrome and associated factors among medical and engineering students in Chennai. Annals of Medical and Health Sciences Research, 4 (2): 179-85, https://doi.org/10.4103/2141-9248.129028, 2014.

7- CRESPO A., SEGU M. and RONDA E.: A reliable and valid questionnaire was developed to measure computer vision syndrome at the workplace. Journal of Clinical Epidemiology, 68 (6): 662-73, doi: 10. 10 16/j.jclinepi.2015. $01.015,2015$.

8- IQBAL M., EL-MASSRY A., ELAGOUZ M. and ELZAMBLY H.: Computer Vision Syndrome Survey among the Medical Students in Sohag University Hospital, Egypt. Ophthalmology Research: An International Journal, 8 (1): 1-8, https://doi.org/10.9734/OR/2018/38436, 2018.

9- REDDY S., LOW C., LIM Y., LOW L., MARDINA F. and NURSALEHA M.: Computer vision syndrome: A study of knowledge and practices in university students. Computer Vision Syndrome Nepal. J. Ophthalmol., 5 (10): 161-8, https://doi.org/10.3126/nepjoph.v5i2.8707, 2013.

10- KHOLA N., ZUNAIRA B., TEHREEM F. and TAHIRA Z.: Prevalence of Computer Vision Syndrome and Its Associated Risk Factors among Under Graduate Medical
Students. Pakistan Journal of Ophthalmology, 32 (3): 140-6, 2016.

11-AL RASHIDI S. and ALHUMAIDAN H.: Computer vision syndrome prevalence, knowledge and associated factors among Saudi Arabia University Students: Is it a serious problem? International Journal of Health Sciences, 11 (5): 17-9, 2017.

12- RAHMAN Z.A. and SANIP S.: Computer user: Demographic and computer related factors that predispose user to get computer vision syndrome. Int. J. Bus. Humanit. Technol., 1: 84-91, 2011.

13- ALEMAYEHU M., NEGA A., TEGEGNE E. and MULE Y.: Prevalence of Self-Reported Computer Vision Syndrome and Associated Factors among Secretaries and Data Processors Who are Working in University of Gondar, Ethiopia. Journal of Biology, Agriculture and Healthcare. Vol. 4, No. 15, 2014.

14- RANASINGHE P., WATHURAPATHA W.S., PERERA Y.S., LAMABADUSURIYA D.A., KULATUNGA S., JAYAWARDANA N. and KATULANDA P.: Computer vision syndrome among computer office workers in a developing country: An evaluation of prevalence and risk factors. BMC Research Notes, 9 (1): 150. https://doi.org/ 10.1186/s13104-016-1962-1, 2016.

15- AGARWAL S., GOEL D. and SHARMA A.: Evaluation of the Factors which Contribute to the Ocular Complaints in Computer Users. Journal of Clinical \& Diagnostic Research, 7 (2): 331-5, 2013.

16- ZAINUDDIN H. and ISA M.: Effect of Human and Technology Interaction: Computer Vision Syndrome among Administrative Staff in a Public University. International Journal of Business, Humanities and Technology, 4 (3): 39-44, 2014

\title{
متلازمة الرؤية الحاسوبية والعوامل المرتبطة بها

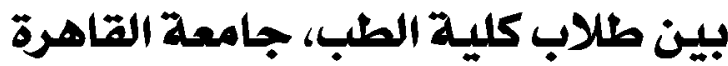

\author{
إن متلازمة الرؤية الحاسوبية هى آحد المشكلات الصحية المتحلقة بإستخدام الحاسب الالى وغيره من آجهزة العرض البصرية الطرفية \\ آمثال الهواتف الذكية والحاسوب المحمول والآجهزة اللوحية. \\ تككون هذه المتلازمة من مجموعة من الآعراض كإجهاد العين، جفاف العين، صداع الرآس، عدم وضوقح الرئية والروئية المزدوجة، إحمرار

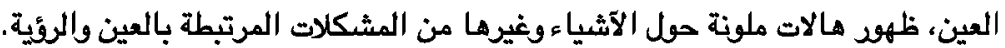 \\ كانت آهداف هذه الدراسة هى تحديد مدى إنتشار متلازمة الرؤية الحاسوبية بين طلاب كلية الطب بجامعة القاهرة، وتقييم الإرتباط بين

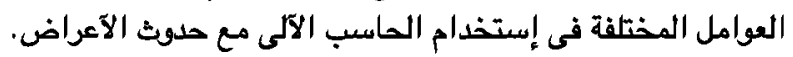

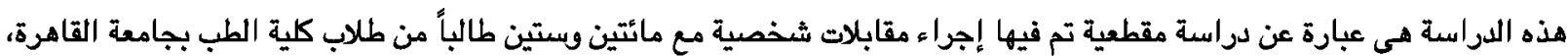

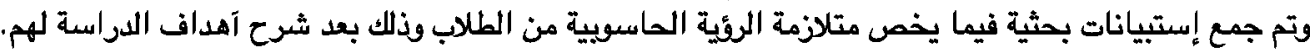

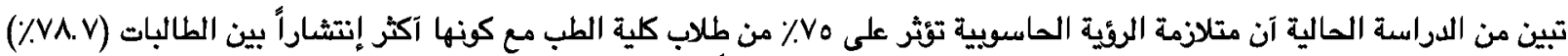

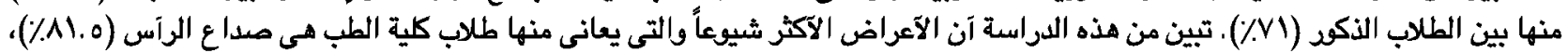

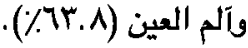

كشفت هذه الدراسة آن متلازمة المؤية الحاسوبية هي مثكلة سائدة بين طلاب كلية الطب، جامعة القاهرة. 